\title{
Switching first-line targeted therapy after not reaching low disease activity within 6 months is superior to conservative approach: a propensity score-matched analysis from the ATTRA registry
}

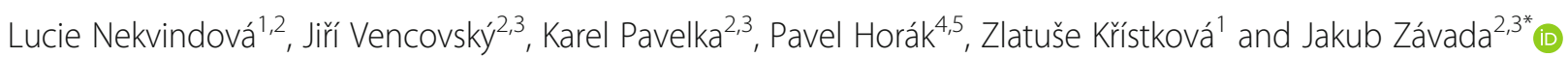

\begin{abstract}
Background: Treat-to-target (T2T) is a widely accepted strategy for patients with rheumatoid arthritis (RA). It recommends attaining a goal of at least low disease activity (LDA) within 6 months; otherwise, the current therapy should be modified. We aimed to investigate whether switching a first-line targeted therapy (TT) in patients not reaching LDA within 6 months leads to a higher probability of meeting LDA at the 12-month visit in daily clinical practice using data from Czech registry ATTRA.

Methods: We included patients with RA starting the first-line $\Pi$ from 1 January 2012 to 31 January 2017 with at least 1-year follow-up. We created four mutually exclusive cohorts based on (1) switching to another $\Pi$ within the first year and (2) reaching a treatment target (DAS28-ESR $\leq 3.2$ ) at the 6-month visit. The primary outcome was the comparison of odds for reaching remission (REM) or LDA at the 12-month visit between patients switching and not switching $\Pi$ after not reaching treatment target at 6 months. Before using logistic regression to estimate the odds ratio, we employed the propensity score to match patients at the 6-month visit.
\end{abstract}

Results: A total of 1275 patients were eligible for the analysis. Sixty-two patients switched within the first 5 months of the treatment before evaluating treatment response at the 6-month visit (C1); 598 patients reached the treatment target within 6 months of therapy (C2); 124 patients did not reach treatment response at 6-month visit and switched to another therapy (C3), and 491 patients continued with the same treatment despite not reaching LDA at the 6-month visit (C4). We matched 75 patients from cohort C3 and 75 patients from C4 using the propensity score. Patients following the T2T principle (C3) showed 2.8 (95\% Cl 1.4-5.8; $p=0.005$ ) times increased likelihood of achieving REM/LDA at the 12-month visit compared to patients not following the T2T strategy (C4).

\footnotetext{
* Correspondence: zavada@revma.cz

${ }^{2}$ Institute of Rheumatology, Na Slupi 4, 12800 Prague, Czech Republic

${ }^{3}$ Department of Rheumatology, First Faculty of Medicine, Prague, Czech Republic

Full list of author information is available at the end of the article
}

(C) The Author(s). 2021 Open Access This article is licensed under a Creative Commons Attribution 4.0 International License, which permits use, sharing, adaptation, distribution and reproduction in any medium or format, as long as you give appropriate credit to the original author(s) and the source, provide a link to the Creative Commons licence, and indicate if changes were made. The images or other third party material in this article are included in the article's Creative Commons licence, unless indicated otherwise in a credit line to the material. If material is not included in the article's Creative Commons licence and your intended use is not permitted by statutory regulation or exceeds the permitted use, you will need to obtain permission directly from the copyright holder. To view a copy of this licence, visit http://creativecommons.org/licenses/by/4.0/. The Creative Commons Public Domain Dedication waiver (http://creativecommons.org/publicdomain/zero/1.0/) applies to the data made available in this article, unless otherwise stated in a credit line to the data. 
(Continued from previous page)

Conclusions: In daily clinical practice, the application of the T2T strategy is underused. Switching $T$ after not reaching REM/LDA within the first 6 months leads to a higher probability of achieving REM/LDA in RA patients at the 12-month visit.

Keywords: Registry, Treat-to-target, Rheumatoid arthritis, Propensity score

\section{Background}

Currently, patients with rheumatoid arthritis (RA) have multiple drug options with different mechanisms of actions to address the heterogeneous nature of the disease. Patients may require multiple successive therapies throughout their lives. In 2010, the European League Against Rheumatism (EULAR) developed its first recommendations for the management of rheumatoid arthritis with synthetic and biological disease-modifying antirheumatic drugs (DMARDs) [1]. There were several updates throughout the years with the last update so far at the end of 2019 [2]. Treating toward a target of remission (REM) or at least a low disease activity (LDA) has become the standard of care for patients. Achievement of the treatment target often requires switching between drugs. According to EULAR recommendations, therapy with conventional synthetic (cs) DMARDs should be started as soon as the diagnosis of RA is made, and methotrexate (MTX) should be the first choice. If the treatment target is not reached with the first csDMARDs, and poor prognostic factors are present (i.e. presence of rheumatoid factor/anti-citrullinated protein antibodies, high disease activity early, joint damage, failure of two or more csDMARDs), a biological (b) DMAR D or targeted synthetic (ts) DMARD should be added. If there is no improvement within 3 months after the start of treatment or if patients have not reached the treatment target with bDMARD/tsDMARD by 6 months, therapy should be adjusted, and treatment with another bDMARD or tsDMARD should be considered [2].

The approach currently recommended for RA treatment involves titrating medication dosages until prespecified disease activity targets (either REM or LDA) have been met and maintaining these targets over time. Such so-called treat-to-target strategies (T2T) have proven to be more effective and to generate better outcomes than usual care $[3,4]$. The efficacy of the T2T approach has been evaluated in many randomised controlled clinical trials [5-11]. Even though the T2T strategy has been widely applied in daily clinical practice nowadays, studies from daily clinical practice concerning the advantage of following T2T over usual care are still required. Several studies evaluating the efficacy of T2T in real clinical practice have been already done $[4,12-$ 17], but more evidence through real-life data is needed to support the implementation of $\mathrm{T} 2 \mathrm{~T}$.
The primary aim of this study was to assess whether following a T2T strategy after not reaching treatment target (REM/LDA) within the first 6 months leads to a higher probability of meeting the treatment target at the 12 -month visit in daily clinical practice. We also described four groups of patients based on different courses of their treatment with the first bDMARD/ tsDMARD.

\section{Methods}

\section{Study setting and data source}

The ATTRA registry, established in 2002, is a prospective, national, observational cohort study. Its main purpose is to evaluate the safety and effectiveness of bDMARDs (and lately also tsDMARDs) in patients with chronic inflammatory rheumatic diseases. Patients with RA (and ankylosing spondylitis, psoriatic arthritis and juvenile idiopathic arthritis) starting bDMARDs or tsDMARDs are recruited from fifty practice sites (private or academic), which captures more than $95 \%$ of patients with RA treated with bDMARDs/ tsDMARDs in the Czech Republic (CZ). Targeted therapy (TT) has been reimbursed for patients with RA if DAS28 > 5.1 despite therapy with csDMARDs until 2019. Since 2019, the cut-off for DAS28 was lowered to 3.2 in CZ. Initial TT should include either TNF inhibitors (TNFis) or tsDMARDs. At the time of this analysis, the ATTRA database included information on 5050 patients with RA.

At the start of therapy, baseline data are collected including demographics (gender, age at diagnosis, age at the start of first-line treatment, height, weight, smoking status, presence of comorbidities), disease characteristics (disease duration, presence of rheumatoid factor (RF) and anti-citrullinated protein antibodies (ACPA), presence of joint erosions on X-ray), disease activity (swollen and tender joint count (0-28), patient global assessment (PTGA) of disease activity and physician global assessment of disease activity (MDGA) on a $100-\mathrm{mm}$ visual analogue scale (VAS; 0-best, 100-worst), erythrocyte sedimentation rate $(\mathrm{ESR}, \mathrm{mg} / \mathrm{h})$ and $\mathrm{C}$-reactive protein $(\mathrm{CRP}, \mathrm{mg} / \mathrm{L}))$ and 28 -joint disease activity score index (DAS28; 0-10) [18], Simplified Disease Activity Index (SDAI, 0-86) [19], Health Assessment Questionnaire (HAQ) for patient function with values from 0 to 3 (the higher, the worse disability) [20], EuroQol EQ-5D questionnaire for quality of life with values from -0.59 to 1 (the higher, the better quality of life) [21], and current or 
previous anti-rheumatic therapies (csDMARDs, bDMARDs, tsDMARDs) and therapy with glucocorticoids (GCs). Follow-up data on disease activity, disease function and anti-rheumatic therapies are collected after 3 and 6 months, and then every 6 months for 3 years, with disease activity and anti-rheumatic therapy data collected annually thereafter.

Ethics approval for ATTRA was granted by the Czech Multicentre Research Ethics Committee, no. 201611 S300, and Institutional Ethics Committee of Institute of Rheumatology, Prague, Czech Republic, no. 10113/2016. No additional ethical approval was required for the current analysis. All subjects provided their written consent for the collection and storage of data before participation. All procedures were performed following the Declaration of Helsinki.

\section{Study population}

In this study, we included all bio-naive adult patients diagnosed with RA starting bDMARDs/tsDMARDs within a period from 1 January 2012 to 31 January 2017 with at least 1-year follow-up. Patients without available DAS28-ESR at baseline, 6-month and 12-month visit or without HAQ and EQ-5D at baseline and 12-month visit were excluded (see Supplementary Figure 1).

\section{Study design}

We divided patients into four cohorts based on a treatment result at the 6-month visit and based on switches to another therapy during the first year of the treatment (Fig. 1). First, we evaluated whether patients switched to another therapy within the first 5 months of the treatment. Next, we assessed if patients reached remission or low disease activity at the 6-month visit (defined as DAS28-ESR $\leq 3.2$ ). Finally, we checked whether patients changed the therapy within months $6-11$ provided they did not achieve the treatment target. Cohort $\mathrm{C} 1$ includes patients that changed bDMARD/tsDMARD therapy during the first months (usually at 3-month visit) before evaluating treatment response at the 6-month visit. These patients were either not responding to the treatment at all, or were not tolerating the treatment (e.g. side effects) within the first months of the first-line therapy. Cohort $\mathrm{C} 2$ consists of patients ideally responding to the treatment because they achieved the treatment target after 6 months of therapy without a need to switch. Cohort C3 comprises the group of patients not responding to the treatment, because they did not achieve the treatment target after the first 6 months of therapy. Following $\mathrm{T} 2 \mathrm{~T}$ principles, they switched to a different treatment. The last cohort $\mathrm{C} 4$ is represented by patients not responding to the treatment since they did not achieve the treatment target (similarly to the C3 cohort). Regardless of T2T principles, they continued with the same treatment.

\section{Objectives and outcome measures}

The primary objective of this study was to compare odds for the achievement of REM or at least LDA after 1 year of the treatment between patients following and not following the T2T strategy (C3 vs $\mathrm{C} 4)$. We assessed disease activity DAS28-ESR index; specifically, LDA was defined as DAS28-ESR $\leq 3.2$ and REM was defined as DAS28ESR $<2.6$. In terms of the secondary outcomes, we compared treatment results based on DAS28-ESR after 12 months between all studied cohorts. The proportion of patients with remission (REM; DAS28-ESR $<2.6$ ), low disease activity (LDA; $2.6 \leq$ DAS28-ESR $\leq 3.2$ ), moderate disease activity (MDA; $3.2<$ DAS28-ESR $\leq 5.1)$ and high disease activity (HDA; DAS28-ESR > 5.1) at baseline and 12 -month visit were compared across the studied cohorts $\mathrm{C} 1-\mathrm{C} 4$. Next, we compared changes in parameters

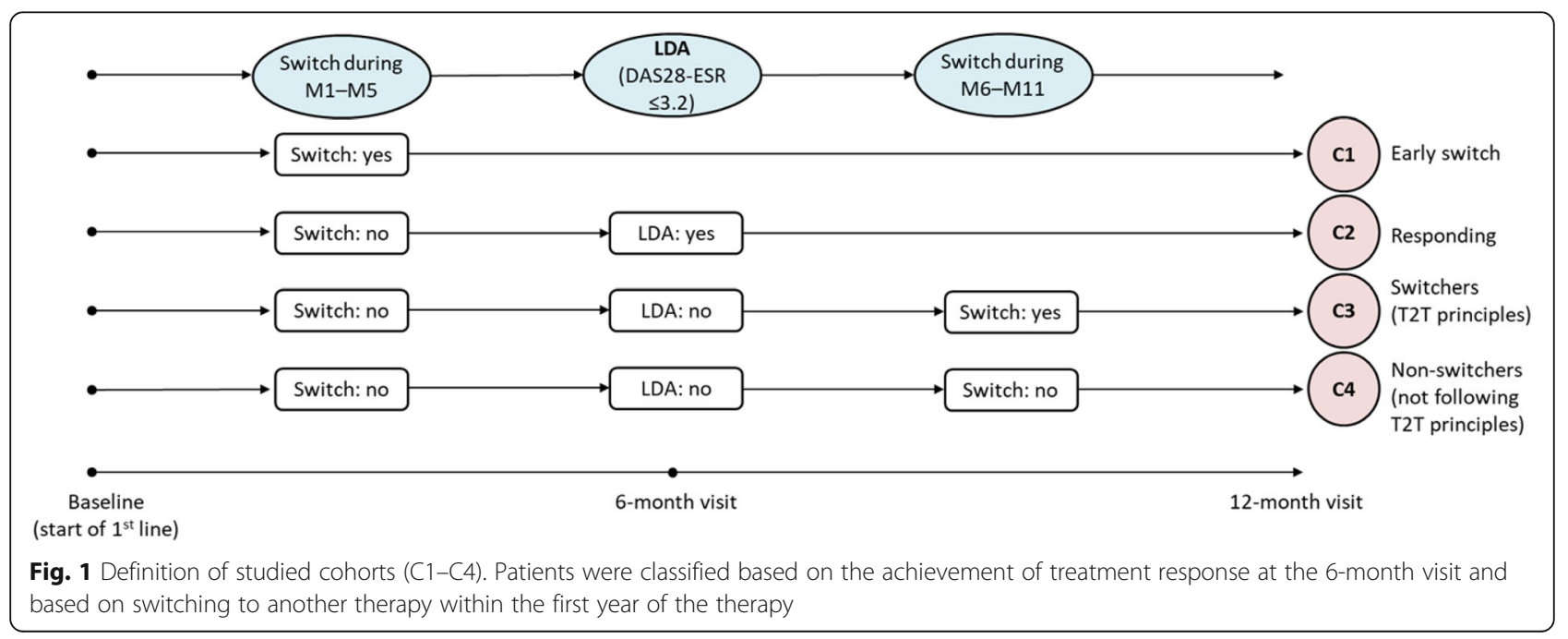


related to disease activity (DAS28-ESR, SDAI, tender and swollen joint count, CRP, ESR, PTGA, MDGA) and quality of life (HAQ-DI, EQ-5D) after 6 and 12 months of the bDMARD/tsDMARD treatment between cohorts $\mathrm{C} 3$ and $\mathrm{C} 4$.

\section{Statistical methods}

Descriptive summary of patients' demographic and treatment characteristics and disease activity measurements was performed for all four studied cohorts $\mathrm{C} 1-\mathrm{C} 4$. For continuous variables, we calculated the median with interquartile range (IQR, 25th-75th percentiles). For a description of categorical variables, we used absolute and relative frequencies (i.e. percentages). To test differences between two patients' groups, we performed the non-parametric Mann-Whitney $U$ test for continuous variables and Pearson's chi-squared test for categorical variables. The magnitude of changes in parameters over two visits was tested through the paired Wilcoxon test. For all tests, $p$ values $<0.05$ were considered to be statistically significant. We did not impute missing data in this analysis and performed a complete-case analysis instead. The percentage of missing data in outcome variables (i.e. DAS28ESR, HAQ and EQ-5D at baseline, 6 and 12 months) was relatively small; we excluded $1.8 \%$ of patients in total.

We used propensity score matching to match patients not switching to another therapy after not reaching treatment target at the 6-month visit $(\mathrm{C} 4)$ to patients switching to a different treatment after not reaching treatment target (C3). For matching, we performed logistic regression with outcome variable C3 $(=1)$ vs C4 $(=0)$ and covariates: gender, age at the start of first-line therapy, disease duration, number of previous csDMARDs, glucocorticoids in previous therapy, swollen joint count, tender joint count, PTGA, ESR, CRP, HAQ, RF positivity, presence of comorbidities, smoking, csDMARDs in concomitant therapy and glucocorticoids in previous therapy. We chose the matching ratio 1:1 and set the calliper to a value 0.2 . We used matching to make both groups comparable in characteristics at the 6-month visit and to minimise confounding by other factors in the evaluation of achieving REM/LDA at the 12 -month visit. After we carried out propensity score matching, we employed binary logistic regression to determine the odds for reaching REM/LDA at the 12month visit in cohorts $\mathrm{C} 3$ and C4. We did all descriptive statistics and testing using IBM SPSS Statistics 25.0. The propensity score model was performed in $\mathrm{R}$ (version 3.5.3).

\section{Results}

\section{Patients' characteristics at baseline}

In total, we included 1275 patients fulfilling the inclusion criteria into the analysis (see Supplementary Figure 1). Cohort $\mathrm{C} 1$ was represented by 62 (4.9\%) patients, $\mathrm{C} 2$ consisted of 598 (46.9\%) patients, C3 included 124 (9.7\%) patients and 491 (38.5\%) patients belonged to C4 subgroup (see Supplementary Figure 1). The most frequently administered drug was bio-original adalimumab (ranging from 27.4 to $40.3 \%$ in studied cohorts), biooriginal etanercept (from 10.5 to $32.3 \%$ ) and golimumab (from 6.5 to 15.5\%). Tofacitinib as the only Janus kinase inhibitor administered in analysed patients was present only in one patient from $\mathrm{C} 2$ and one patient from $\mathrm{C} 4$. Out of 61 patients from $\mathrm{C} 1$ treated with TNFi in the first line, $42(68.9 \%)$ switched before the 6-month visit to another TNFi, 11 (18.0\%) switched to an interleukin-6 inhibitor (tocilizumab or sarilumab), 7 (11.5\%) switched to abatacept and $1(1.6 \%)$ switched to rituximab. One patient from $\mathrm{C} 1$ who was treated with tocilizumab in the first line switched to anakinra. Out of 120 patients from the $\mathrm{C} 3$ cohort that were treated with TNFi, $72(60.0 \%)$ patients switched after the 6 months to another TNFi, 28 (23.3\%) switched to an interleukin-6 drug (tocilizumab or sarilumab), 13 (10.8\%) switched to abatacept and 7 (5.8\%) switched to rituximab. Out of two C3 patients with tocilizumab, one switched to rituximab and the other to abatacept. Out of two C3 patients with rituximab, one switched to etanercept and the other to abatacept.

We present baseline characteristics of all four studied cohorts in Table 1. The median age at the start of the first bDMARD/tsDMARD was between 51 years (C1) and 55 years (C4 cohort). Females represented from $72.1 \%$ (C2 cohort) to $83.9 \%$ (C1 cohort) patients. Patients from all studied cohorts had high baseline disease activity according to DAS28-ESR score with median 6.4 (5.7-7.0) in C1, 5.9 (5.3-6.5) in C2, $6.2(5.6-6.8)$ in C3 and $6.3(5.8-6.8)$ in C4. Patients from cohorts C3 and C4 significantly differed only in age at the start of the first therapy $(p=0.016)$ and the number of previous csDMARDs $(p=0.025)$. The median age was 52.0 (44.5-61.0) years in C3 and 55.0 (48.0-63.0) years in C4. Cohorts $\mathrm{C} 1$ and $\mathrm{C} 2$ significantly differed in gender $(84 \%$ vs $72 \%$ females; $p=0.046)$ and in almost all parameters related to baseline disease activity and quality of life. Patients from cohort $\mathrm{C} 1$ had higher disease activity than the $\mathrm{C} 2$ cohort according to DAS28-ESR (median 6.4 vs $5.9 ; p<0.001$ ), TJC (median 14 vs $12 ; p=0.005)$, CRP (median 22 vs $12 ; p=$ 0.002 ), PTGA (median 78 vs $70 ; p=0.008$ ), MDGA (median 74 vs $65 ; p=0.015$ ) and worse physical function and quality of life according to HAQ-DI (median 1.8 vs $1.4 ; p=0.001$ ) and EQ-5D (median 0.1 vs 0.2 ; $p=0.048$ ), respectively. Additional baseline characteristics including the presence of comorbidities, BMI, drug usage, number of concomitant csDMARDs and MTX and prednisone doses are presented in Supplementary Table 1. 
Table 1 Baseline characteristics of patients in cohorts $\mathrm{C} 1-\mathrm{C} 4(\mathrm{~N}=1275)$

\begin{tabular}{|c|c|c|c|c|}
\hline & $\mathrm{C} 1(n=62)$ & C2 $(n=598)$ & C3 $(n=124)$ & C4 $(n=491)$ \\
\hline Female, $n(\%)$ & $52(83.9 \%)$ & $431(72.1 \%)$ & $102(82.3 \%)$ & $390(79.4 \%)$ \\
\hline Age at diagnosis, years, median (IQR) & $44.0(34.0-52.0)$ & $43.5(33.0-52.0)$ & $45.0(34.0-51.5)$ & $47.0(38.0-54.0)$ \\
\hline Age at start of 1st line, years, median (IQR) & $51.0(42.0-58.0)$ & $53.0(41.0-60.0)$ & $52.0(44.5-61.0)$ & $55.0(48.0-63.0)$ \\
\hline Disease duration, years, median (IQR) & $5.6(3.0-7.8)$ & $6.0(2.5-11.8)$ & $5.0(2.2-12.1)$ & $6.2(3.0-12.9)$ \\
\hline RF positive, $n(\%)$ & $47(75.8 \%)$ & $428(71.6 \%)$ & $92(74.2 \%)$ & $389(79.6 \%)$ \\
\hline ACPA positive, n/total (\%) & $44 / 61(72.1 \%)$ & $399 / 587(68.0 \%)$ & $91 / 120(75.8 \%)$ & $348 / 480(72.5 \%)$ \\
\hline Presence of erosions, n/total (\%) & 25/38 (65.8\%) & 210/295 (71.2\%) & $46 / 67(68.7 \%)$ & $22 / 290(76.6 \%)$ \\
\hline Currently smoking, n/total (\%) & 10/53 (18.9\%) & $102 / 504(20.2 \%)$ & 26/103 (25.2\%) & 93/413 (22.5\%) \\
\hline \multicolumn{5}{|l|}{ Number of previous csDMARDs, $n(\%)$} \\
\hline 0 & $0(0.0 \%)$ & $8 / 592(1.4 \%)$ & $2(1.6 \%)$ & 6/484 (1.2\%) \\
\hline 1 & $13(21.0 \%)$ & 226/592 (38.2\%) & $27(21.8 \%)$ & $131 / 484(27.1 \%)$ \\
\hline 2 & $18(29.0 \%)$ & 147/592 (24.8\%) & $30(24.2 \%)$ & 165/484 (34.1\%) \\
\hline 3 & $17(27.4 \%)$ & 112/592 (18.9\%) & 35 (28.2\%) & $113 / 484(23.3 \%)$ \\
\hline $4+$ & $14(22.6 \%)$ & $99 / 592(16.7 \%)$ & $30(24.2 \%)$ & 69/484 (14.3\%) \\
\hline Glucocorticoids in previous history, $n(\%)$ & $56(90.3 \%)$ & $519 / 597(86.9 \%)$ & $112(90.3 \%)$ & $442(90.0 \%)$ \\
\hline Concomitant csDMARDs, $n$ (\%) & $54(87.1 \%)$ & $549(91.8 \%)$ & $107(86.3 \%)$ & $440(89.6 \%)$ \\
\hline Concomitant MTX, n (\%) & $44(71.0 \%)$ & $454(75.9 \%)$ & $77(62.1 \%)$ & 349 (71.1\%) \\
\hline Concomitant GCs, n (\%) & $49(79.0 \%)$ & $446(74.6 \%)$ & $96(77.4 \%)$ & $402(81.9 \%)$ \\
\hline DAS28-ESR (0-10), median (IQR) & $6.4(5.7-7.0)$ & $5.9(5.3-6.5)$ & $6.2(5.6-6.8)$ & $6.3(5.8-6.8)$ \\
\hline TJC (28 joints), median (IQR) & $14.0(11.0-19.0)$ & $12.0(9.0-16.0)$ & $14.5(9.0-19.0)$ & $13.0(10.0-18.0)$ \\
\hline SJC (28 joints), median (IQR) & $10.0(7.0-13.0)$ & $9.0(6.0-12.0)$ & $9.5(6.0-12.5)$ & $10.0(7.0-13.0)$ \\
\hline ESR (mm/h), median $(\mathrm{IQR})^{\mathrm{a}}$ & $33.5(16.0-53.0)$ & $28.0(16.0-40.0)$ & $32.0(18.0-50.0)$ & $34.0(23.0-50.0)$ \\
\hline CRP (mg/l), median (IQR) & $22.0(9.4-34.0)$ & $12.0(5.3-23.5)$ & $15.0(7.9-31.0)$ & $16.8(8.0-33.1)$ \\
\hline SDAI (0-86), median (IQR) & $40.5(32.7-47.8)$ & $35.6(29.5-42.4)$ & $39.3(33.0-48.2)$ & $39.0(32.6-45.9)$ \\
\hline PTGA (0-100), median (IQR) & $78.0(69.0-84.0)$ & $70.0(59.0-80.0)$ & $75.0(62.5-81.5)$ & $75.0(60.0-85.0)$ \\
\hline MDGA (0-100), median (IQR) & $74.0(60.0-80.0)$ & $65.0(52.0-75.0)$ & $70.0(58.5-80.0)$ & $70.0(60.0-80.0)$ \\
\hline HAQ-DI (0-3), median (IQR) & $1.8(1.3-2.0)$ & $1.4(1.0-1.8)$ & $1.8(1.4-2.0)$ & $1.8(1.4-2.0)$ \\
\hline EQ-5D (- 0.59-1), median (IQR) & $0.1(0.0-0.6)$ & $0.2(0.1-0.7)$ & $0.1(0.0-0.5)$ & $0.1(0.0-0.5)$ \\
\hline
\end{tabular}

$I Q R$ interquartile range, $R F$ rheumatoid factor, $A C P A$ anti-citrullinated protein, $T N F i$ tumour necrosis factor inhibitor, csDMARDs conventional synthetic diseasemodifying anti-rheumatic drugs, MTX methotrexate, DAS28-ESR 28-joint disease activity score with ESR, TJC tender joint count, SJC swollen joint count, ESR erythrocyte sedimentation rate, CRP C-reactive protein, SDAI Simplified Disease Activity Index, PTGA patient general assessment of disease activity, MDGA physician general assessment of disease activity, HAQ-DI Health Assessment Questionnaire, EQ-5D EuroQol 5 Dimension for measuring the quality of life

${ }^{a} n=62(C 1), n=573(C 2), n=118(C 3), n=486$ (C4)

${ }^{\mathrm{b}} n=60(\mathrm{C} 1), n=576(\mathrm{C} 2), n=123(\mathrm{C} 3), n=480$ (C4)

${ }^{c} n=55$ (C1), $n=560(C 2), n=119$ (C3), $n=465$ (C4)

${ }^{d} n=57(C 1), n=582(C 2), n=120(C 3), n=476(C 4)$

\section{Disease activity after 3 months in C1-C4}

Disease activity according to DAS28-ESR score after 3 months of the first-line treatment in cohorts $\mathrm{C} 1-\mathrm{C} 4$ is shown in Supplementary Figure 2. We observed the highest proportion of patients with REM/LDA after 3 months in cohort $\mathrm{C} 2$ in almost $70 \%$ of patients. This result was statistically significantly higher compared to other cohorts $(p<0.001)$. There was also a statistically significant difference in the proportion of patients with REM/LDA between patients in the groups C3 and C4. While in group C3 it was $10.6 \%$ of patients, in group $C 4$ it was $20.4 \%(p=0.016)$. The median value of DAS28-
ESR in group $\mathrm{C} 1$ corresponded to the high disease activity range; group $\mathrm{C} 2$ had median DAS28-ESR belonging to low disease activity; the median DAS28-ESR value in cohorts C3 and C4 fell into the category of moderate disease activity.

\section{Disease activity after 12 months in C1-C4}

Comparison of disease activity according to the DAS28ESR score after 1 year of treatment in cohorts $\mathrm{C} 1-\mathrm{C} 4$ is illustrated in Fig. 2. We could see the best treatment results after 12 months in group C2 with almost 79\% patients with REM/LDA compared to $48 \%$ patients in 
group C1 $(p<0.001), 40 \%$ patients in group C3 $(p<$ $0.001)$ and $32 \%$ in group $C 4 \quad(p<0.001)$. Although there was no statistically significant difference in the proportion of patients with REM/LDA between groups C3 (following T2T strategy) and $\mathrm{C} 4$ (not following T2T strategy) after 12 months $(p=0.095)$, we could observe slightly better results in group C3 $(40 \%$ vs $32 \%$ with REM/LDA). We observed the lowest median value of DAS28-ESR in group C2, and it falls within the level of remission. The median value of DAS28-ESR in group C1 corresponded to the upper bound of low disease activity, and median DAS28-ESR values in groups C3 and C4 were within the range of moderate disease activity.

\section{Comparison of cohorts C3 and C4 at 6-month and 12- month visit}

At the 6-month visit, patients from groups $\mathrm{C} 3$ and $\mathrm{C} 4$ differed in all tested parameters related to disease activity and quality of life (Table 2). We observed lower disease activity and better quality of life in C4. Patients from C3 and C4 did not significantly differ in concomitant therapy, but numerically more changes in dosage of glucocorticoids and methotrexate have been observed in the C3 cohort compared to the C4 cohort between M6 and M12 (see Supplementary Table 2). At the 12-month visit, patients from both groups did not significantly differ in most of the parameters related to disease activity; they only differed in PTGA $(p=0.044)$ and EQ-5D $(p=$ 0.017). In terms of the magnitude of changes across the two visits, patients from C3 significantly improved in all parameters related to disease activity and quality of life (see Supplementary Table 3). Patients from C4 did not significantly improve in CRP and HAQ-DI. In the comparison of the size of changes between the two groups, patients from C3 showed better results (i.e. more significant improvements) in all tested parameters (see Supplementary Table 3).

\section{Odds for treatment target in C3 vs C4 at the 12-month visit}

We employed propensity score matching to reduce selection bias by adjusting for potential confounding factors at the 6-month visit. We show a description of patients' characteristics at the 6-month visit after using propensity score matching in Table 3 . Both groups included 75 patients after the matching. Density plots of propensity score before and after matching are displayed in Supplementary Figure 3. Patients did not differ anymore in parameters related to disease activity and quality of life (see Table 3). The most frequently administered drugs at the 12-month visit were tocilizumab (27\%), certolizumab (17\%), abatacept (15\%) and etanercept (12\%) in C3. Patients from C4 were most frequently treated with adalimumab (35\%), etanercept $(21 \%)$, golimumab (16\%) and certolizumab (13\%). To compare odds for reaching treatment target at the 12 -month visit in patients following the T2T principle at 6-month visit (C3) vs patients staying on the first treatment (C4), we employed a logistic regression model with outcome DAS28-ESR $\leq 3.2$. Patients following the T2T principle
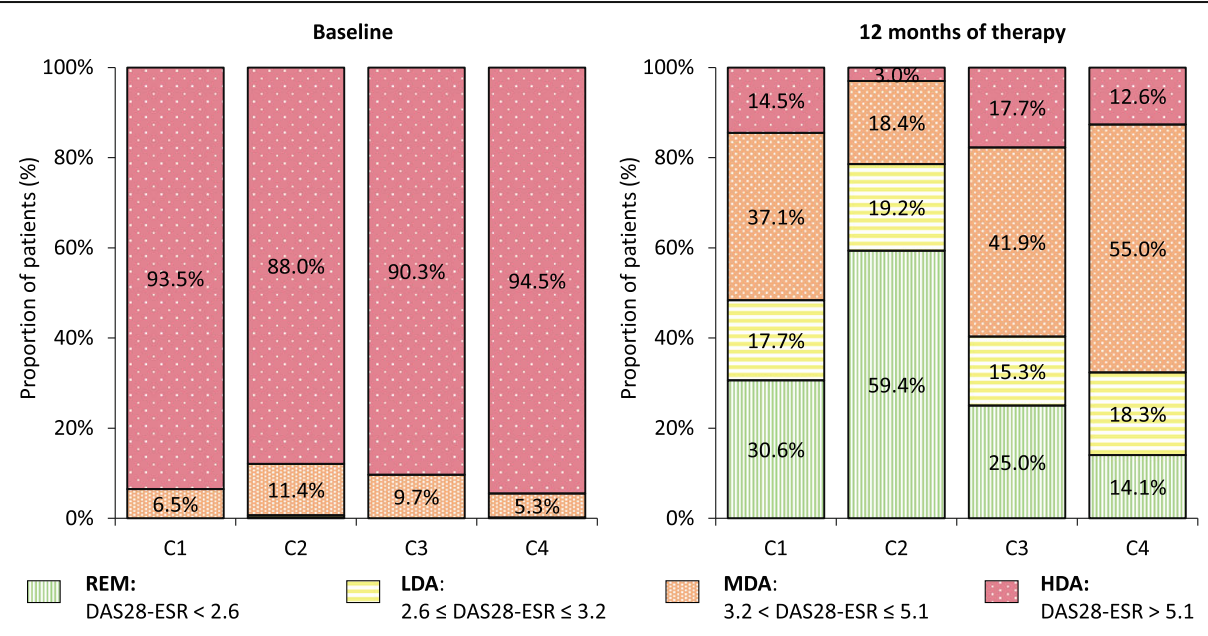

\begin{tabular}{llcccc}
\hline Month & DAS28-ESR & $\mathrm{C} 1(n=62)$ & $\mathrm{C} 2(n=598)$ & $\mathrm{C} 3(n=124)$ & $\mathrm{C} 4(n=491)$ \\
\hline $\mathbf{0}$ & Median (IQR) & $6.4(5.7-7.0)$ & $5.9(5.3-6.5)$ & $6.2(5.6-6.8)$ & $6.3(5.8-6.8)$ \\
\hline \multirow{2}{*}{$\mathbf{1 2}$} & REM+LDA & $30(48.4 \%)$ & $470(78.6 \%)$ & $50(40.3 \%)$ & $159(32.4 \%)$ \\
& Median (IQR) & $3.2(2.4-4.3)$ & $2.4(1.7-3.1)$ & $3.7(2.6-4.7)$ & $3.7(3.0-4.4)$ \\
\hline
\end{tabular}

Fig. 2 Disease activity according to DAS28-ESR at baseline and after 1 year of treatment. DAS28-ESR, 28-joint disease activity score with erythrocyte sedimentation; REM, remission; LDA, low disease activity; MDA, moderate disease activity; HDA, high disease activity; IQR, interquartile range 
Table 2 Comparison of parameters related to disease activity, quality of life and concomitant therapy between C3 and C4 cohorts at the 6-month and 12-month visit

\begin{tabular}{|c|c|c|c|c|c|c|}
\hline & \multicolumn{3}{|l|}{6 months } & \multicolumn{3}{|l|}{12 months } \\
\hline & C3 $(n=124)$ & C4 $(n=491)$ & $p$ value & C3 $(n=124)$ & C4 $(n=491)$ & $p$ value \\
\hline DAS28-ESR (0-10) & $5.4(4.6-6.3)$ & $4.0(3.5-4.5)$ & $<0.001$ & $3.7(2.6-4.7)$ & $3.7(3.0-4.4)$ & 0.710 \\
\hline TJC (28 joints) & $9.0(4.0-14.0)$ & $3.0(2.0-5.0)$ & $<0.001$ & $3.0(1.0-7.0)$ & $2.0(1.0-5.0)$ & 0.490 \\
\hline SJC (28 joints) & $6.0(2.0-9.5)$ & $2.0(1.0-4.0)$ & $<0.001$ & $2.0(0.0-4.0)$ & $2.0(0.0-3.0)$ & 0.498 \\
\hline $\operatorname{ESR}(\mathrm{mm} / \mathrm{h})$ & $28.0(16.5-46.5)$ & $22.0(13.0-33.0)$ & $<0.001$ & $16.5(6.5-32.0)$ & $19.0(11.0-30.5)$ & 0.052 \\
\hline CRP (mg/l) & $15.0(7.9-28.9)$ & $5.7(2.5-13.7)$ & $<0.001$ & $4.7(1.6-17.0)$ & $5.0(2.3-11.3)$ & 0.766 \\
\hline SDAI (0-86) & $30.2(19.7-39.5)$ & $13.9(10.7-18.3)$ & $<0.001$ & $13.8(8.0-20.9)$ & $11.3(7.7-17.4)$ & 0.093 \\
\hline PTGA (0-100) & $61.0(50.0-75.0)$ & $40.0(26.0-50.0)$ & $<0.001$ & $36.0(25.0-60.0)$ & $33.0(20.0-50.0)$ & 0.044 \\
\hline MDGA (0-100) & $58.0(40.0-70.0)$ & $30.0(20.0-40.0)$ & $<0.001$ & $25.0(15.0-45.0)$ & $25.0(15.0-40.0)$ & 0.812 \\
\hline HAQ-DI (0-3) & $1.5(1.1-1.9)$ & $1.3(0.9-1.6)$ & $<0.001$ & $1.3(0.9-1.9)$ & $1.3(0.9-1.6)$ & 0.140 \\
\hline EQ-5D (-0.59-1) & $0.2(0.1-0.7)$ & $0.7(0.5-0.7)$ & $<0.001$ & $0.6(0.1-0.7)$ & $0.7(0.5-0.8)$ & 0.017 \\
\hline Concomitant csDMARDs & $98(79.0 \%)$ & $414(84.3 \%)$ & 0.159 & $94(75.8 \%)$ & 407 (82.9\%) & 0.070 \\
\hline Concomitant MTX & 79 (63.7\%) & 341 (69.5\%) & 0.220 & 77 (62.1\%) & $332(67.6 \%)$ & 0.245 \\
\hline Concomitant GCs & 95 (76.6\%) & 374 (76.2\%) & 0.918 & $92(74.2 \%)$ & 370 (75.4\%) & 0.789 \\
\hline
\end{tabular}

Continuous variables are described through the median (interquartile range); categorical variables are characterised by $n$ (\%)

DAS28-ESR 28-joint disease activity score with ESR, TJC tender joint count, SJC swollen joint count, ESR erythrocyte sedimentation rate, CRP C-reactive protein, SDAI Simplified Disease Activity Index, PTGA patient general assessment of disease activity, MDGA physician general assessment of disease activity, HAQ-DI Health Assessment Questionnaire, EQ-5D EuroQol 5 Dimension for measuring the quality of life, csDMARDs conventional synthetic disease-modifying anti-rheumatic drugs, MTX methotrexate, GCs glucocorticoids

(C3) showed 2.8 (CI 1.4-5.8) times higher odds for reaching at least LDA at the 12 -month visit $(p=0.005)$ compared to patients not following the T2T principle (C4). In group C3, $41 \%$ of patients achieved at least REM/LDA at the 12-month visit, while in group C4, it was $20 \%$ (see Supplementary Table 4).

\section{Discussion}

In this prospective observational cohort study from real clinical practice in the Czech Republic, we have shown that following the T2T strategy and switching the targeted drug to another therapy after not reaching REM/ LDA at the 6-month visit increases the chance of achieving REM/LDA at the 12-month visit as opposed to patients not following the treatment target. This finding support results from previous studies showing that T2T is efficient in daily clinical practice. Our study also provided a summary of four different courses of treatment management during the first year of bDMARD/ tsDMARD therapy. We created four patients' cohorts based on switching the treatment and based on reaching a treatment target at 6 months. We described all four patients' groups at baseline and compared their treatment results after 1 year of treatment. Furthermore, we evaluated disease activity and quality of life at 6 months in groups $\mathrm{C} 3$ and $\mathrm{C} 4$ and compared the sizes of changes from the 6-month to the 12-month visit. We observed that patients not following the T2T at the 6-month visit (C4) had lower disease activity and better quality of life at 6 months than patients following T2T and switching to another therapy after not reaching the treatment target (C3). However, patients following the T2T strategy showed a more significant improvement both in disease activity and quality of life within the period from the 6month visit to the 12-month visit. Patients from cohort C3 also had a higher rate of REM/LDA at 12 months in comparison with $\mathrm{C} 4$ (though not statistically significant; $p=0.095)$.

A similar study investigated whether a tight control treatment strategy (i.e. optimising treatment by measurement of disease activity in order to make treatment adjustments to reach a predefined target LDA/REM) in early RA is more effective than treatment according to usual care in reaching REM (DAS28 $<2.6$ ) after 1 year [4]. They compared two distinct early RA cohorts from two different regions in the Netherlands: the usual care cohort and the 'tight control' cohort. The OR adjusted for baseline DAS28 was 3.1 (95\% CI 1.8-5.2). Therefore, patients treated according to tight control had approximately three times higher odds to reach REM at 1 year after the baseline. This result is very similar to the OR obtained in our study, though we evaluated achievement of LDA/REM instead. In another similar study, Norwegian authors compared patients following a T2T strategy (2010-2015) with patients from the pre-T2T cohort (2006-2009) following routine care [13]. They assessed the 2-year effect on disease activity and health-related quality of life and showed significantly higher odds (multivariable OR $1.89,95 \%$ CI 1.33-2.68) for SDAI remission $(\leq 3.3)$ in patients following a T2T strategy. Within 
Table 3 Description of patients from C3 and C4 cohorts at the 6-month visit after applying propensity score matching

\begin{tabular}{|c|c|c|c|}
\hline & $\mathrm{C} 3(n=75)$ & C4 $(n=75)$ & $p$ value \\
\hline Female, $n(\%)^{*}$ & $60(80.0 \%)$ & $61(81.3 \%)$ & 0.836 \\
\hline Age at diagnosis, years, median (IQR) & $45.0(36.0-53.0)$ & $45.0(37.0-53.0)$ & 0.678 \\
\hline Age at start of 1st line, years, median (IQR)* & $52.0(45.0-61.0)$ & $55.0(44.0-61.0)$ & 0.811 \\
\hline Disease duration, years, median (IQR)* & $5.0(2.4-12.7)$ & $5.8(3.0-13.1)$ & 0.937 \\
\hline RF positive, $n(\%)^{*}$ & $60(80.0 \%)$ & $54(72.0 \%)$ & 0.251 \\
\hline Presence of comorbidities, $n(\%)^{*}$ & $54(72.0 \%)$ & $55(73.3 \%)$ & 0.855 \\
\hline Currently smoking, $n(\%)^{*}$ & $21(28.0 \%)$ & $21(28.0 \%)$ & 1.000 \\
\hline \multicolumn{4}{|l|}{ Number of previous csDMARDs, $n(\%)^{*}$} \\
\hline 0 & $2(2.7 \%)$ & $0(0.0 \%)$ & \multirow[t]{5}{*}{0.230} \\
\hline 1 & $16(21.3 \%)$ & $15(20.0 \%)$ & \\
\hline 2 & $20(26.7 \%)$ & $28(37.3 \%)$ & \\
\hline 3 & $17(22.7 \%)$ & $20(26.7 \%)$ & \\
\hline $4+$ & $20(26.7 \%)$ & $12(16.0 \%)$ & \\
\hline Glucocorticoids in previous history, $n(\%)^{*}$ & 67 (89.3\%) & $66(88.0 \%)$ & 0.797 \\
\hline Concomitant csDMARDs, $n(\%)^{*}$ & $61(81.3 \%)$ & $63(84.0 \%)$ & 0.666 \\
\hline Concomitant GCs, $n(\%)^{*}$ & $56(74.7 \%)$ & $55(73.3 \%)$ & 0.852 \\
\hline DAS28-ESR (0-10), median (IQR) & $5.0(4.2-5.9)$ & $5.0(4.1-5.7)$ & 0.717 \\
\hline TJC (28 joints), median (IQR)* & $8.0(4.0-12.0)$ & $6.0(3.0-11.0)$ & 0.677 \\
\hline SJC (28 joints), median (IQR)* & $4.0(2.0-8.0)$ & $4.0(2.0-7.0)$ & 0.973 \\
\hline $\operatorname{ESR}(\mathrm{mm} / \mathrm{h})$, median $(\mathrm{IQR})^{*}$ & $27.0(15.0-37.0)$ & $25.0(12.0-41.0)$ & 0.844 \\
\hline $\mathrm{CRP}(\mathrm{mg} / \mathrm{l})$, median $(\mathrm{IQR})^{*}$ & $15.0(8.0-22.2)$ & $8.4(3.5-25.7)$ & 0.090 \\
\hline SDAI (0-86), median (IQR) & $25.5(15.6-34.9)$ & $22.7(16.1-30.9)$ & 0.531 \\
\hline PTGA (0-100), median (IQR)* & $60.0(40.0-71.0)$ & $50.0(40.0-71.0)$ & 0.519 \\
\hline MDGA (0-100), median (IQR) & $55.0(35.0-70.0)$ & $45.0(30.0-60.0)$ & 0.059 \\
\hline HAQ-DI (0-3), median (IQR)* & $1.5(1.1-1.9)$ & $1.5(1.1-1.9)$ & 0.877 \\
\hline EQ-5D (-0.59-1), median (IQR) ${ }^{\mathrm{a}}$ & $0.2(0.1-0.7)$ & $0.6(0.1-0.7)$ & 0.290 \\
\hline
\end{tabular}

These parameters were included in the propensity score model

$I Q R$ interquartile range, $R F$ rheumatoid factor, csDMARDs conventional synthetic disease-modifying anti-rheumatic drugs, GCs glucocorticoids, DAS28-ESR 28-joint disease activity score with ESR, TJC tender joint count, SJC swollen joint count, ESR erythrocyte sedimentation rate, CRP C-reactive protein, SDAI Simplified Disease Activity Index, PTGA patient general assessment of disease activity, MDGA physician general assessment of disease activity, HAQ-DI Health Assessment Questionnaire, EQ-5D EuroQol 5 Dimension for measuring the quality of life ${ }^{\mathrm{a}} n=74$ (C3), $n=75$ (C4)

secondary outcomes, they also evaluated REM, according to DAS28 (OR 2.15, 95\% CI 1.51-3.06).

A Dutch study investigated the 3-year results of a protocolised T2T strategy in daily clinical practice [16]. The authors found out that $\mathrm{T} 2 \mathrm{~T}$ leads to high remission rates, improved physical function and quality of life, and limited radiographic damage after 3 years in daily clinical practice. In another study from the Netherlands, the authors described a 5-year continuous application of a T2T strategy in patients with early RA in daily clinical practice and confirmed the favourable disease- and patient-related outcomes [12]. A longitudinal study of RA patients from 10 countries (RA BIODAM) investigated whether following a T2T strategy in daily clinical practice leads to more patients meeting REM [14]. Application of T2T every 3 months did not yield a higher likelihood of REM according to DAS44 and DAS28 3 months later, but sustained T2T (i.e. T2T followed in at least two consecutive visits) resulted in an increased likelihood of achieving DAS44 REM (OR 1.19, 95\% CI 1.03-1.39).

Our study has shown that a substantial number of patients did not follow the T2T strategy and continued with the same treatment after not reaching the treatment target within 6 months. This finding is probably not unique for the Czech Republic. Others have also shown that the T2T strategy is underused in real clinical practice; e.g. in the analysis from the Corrona RA registry, a considerable proportion of patients continued without changing/accelerating treatment despite not reaching an adequate response to the initial TNF inhibitor therapy at 6 and 12 months [22]. 
Although the present study has a limitation of the absence of randomisation, we have partially overcome this problem by employing the propensity score matching at the 6-month visit. Thus, we have minimised confounding by other factors, and we obtained the effect of following/not following the T2T principle in the evaluation of REM/LDA at the 12-month visit. A possible limitation of this study could be an absence of monitoring treatment intensification through increased dosages. Further, our study only concerned the first-line bDMARD/ tsDMARD therapy. Thus, evaluating of implementation of the T2T strategy within subsequent lines of therapy could be a possible subject for future studies.

\section{Conclusion}

In conclusion, the application of $\mathrm{T} 2 \mathrm{~T}$ principles and switching to another bDMARD/tsDMARD after not reaching REM/LDA within the first 6 months of bDMARD/tsDMARD treatment leads to a higher probability of achieving REM/LDA in RA patients at the 12month visit. In this study, the T2T strategy showed superiority over traditional routine care in daily clinical practice.

\section{Supplementary Information}

The online version contains supplementary material available at https://doi. org/10.1186/s13075-020-02393-8.

\section{Additional file 1: Supplementary Table 1. Additional baseline} characteristics of patients in cohorts C1-C4 ( N=1275).

Additional file 2: Supplementary Table 2. Changes in comedication with glucocorticoids and methotrexate during the first year in cohorts C1-C4.

Additional file 3: Supplementary Table 3. Comparison of differences in parameters from month 6 to 12 between cohort C3 and C4.

Additional file 4: Supplementary Table 4. Results of logistic regression with outcome DAS28-ESR $\leq 3.2$ for C3 vs C4.

Additional file 5: Supplementary Figure 1. Flow chart showing individual steps to final dataset (a) and division into four cohorts (b).

Additional file 6: Supplementary Figure 2. Disease activity according to DAS28-ESR after three months of treatment.

Additional file 7: Supplementary Figure 3. Propensity score densities of cohorts C3 and C4 before and after matching.

\section{Abbreviations}

ACPA: Anti-citrullinated protein antibodies; bDMARDs: Biological diseasemodifying anti-rheumatic drugs; Cl: Confidence interval; CRP: C-reactive protein; CSDMARDs: Conventional synthetic disease-modifying anti-rheumatic drugs; CZ: Czech Republic; DAS28-ESR: 28-joint disease activity score using the erythrocyte sedimentation rate; DMARD: Disease-modifying antirheumatic drug; EQ-5D: EuroQol-5 Dimensions; ESR: Erythrocyte sedimentation rate; EULAR: European League Against Rheumatism; GCs: Glucocorticoids; HAQ-DI: Health Assessment Questionnaire Disability Index; HDA: High disease activity; IQR: Interquartile range; LDA: Low disease activity; MDA: Moderate disease activity; MDGA: Physician global assessment of disease activity; MTX: Methotrexate; OR: Odds ratio; PTGA: Patient global assessment of disease activity; RA: Rheumatoid arthritis; REM: Remission; RF: Rheumatoid factor: SDAl: Simplified disease activity index: T2T: Treat-totarget; TNFi: Tumour necrosis factor inhibitor; tsDMARDs: Targeted disease- modifying anti-rheumatic drugs; TT: Targeted therapy; VAS: Visual analogue scale

\section{Acknowledgements}

Not applicable.

\section{Authors' contributions}

All authors were involved in drafting the manuscript or revising it critically for content. LN planned and performed the analysis, interpreted patients' data and wrote the manuscript. JV, KP and PH revised the manuscript. ZK managed the project. JZ designed the project, supervised its conduct and helped to write the manuscript. All authors read and approved the final manuscript.

\section{Funding}

This work was supported by the project (Ministry of Health, Czech Republic) for conceptual development of research organisation 00023728 (Institute of Rheumatology).

Availability of data and materials

The datasets analysed during the current study are available from the corresponding author on reasonable request. Requests will be considered by the Czech Rheumatological Society.

\section{Ethics approval and consent to participate}

All procedures in this study were in accordance with the ethical standards of the institutional and national research committee (Czech Multicentre Research Ethics Committee, no. 201611 S300, and Institutional Ethics Committee of Institute of Rheumatology, Prague, Czech Republic, no. 10113/ 2016) and with the 1964 Helsinki declaration and its later amendments. All subjects provided their written consent for the collection and storage of data before participation.

Consent for publication

Not applicable.

\section{Competing interests}

The authors declare that they have no competing interests.

\section{Author details}

${ }^{1}$ Institute of Biostatistics and Analyses, Ltd., Brno, Czech Republic. ${ }^{2}$ Institute of Rheumatology, Na Slupi 4, 12800 Prague, Czech Republic. ${ }^{3}$ Department of Rheumatology, First Faculty of Medicine, Prague, Czech Republic. ${ }^{4}$ Department of Internal Medicine III - Nephrology, Rheumatology, Endocrinology, Faculty of Medicine and Dentistry, Palacký University, Olomouc, Czech Republic. ${ }^{5}$ University Hospital, Olomouc, Czech Republic.

Received: 11 September 2020 Accepted: 13 December 2020 Published online: 06 January 2021

\section{References}

1. Smolen JS, Landewé R, Breedveld FC, Dougados M, Emery P, Gaujoux-Viala $C$, et al. EULAR recommendations for the management of rheumatoid arthritis with synthetic and biological disease-modifying antirheumatic drugs. Ann Rheum Dis. 2010;69(6):964-75.

2. Smolen JS, Landewé RBM, Bijlsma JWJ, Burmester GR, Dougados M, Kerschbaumer A, et al. EULAR recommendations for the management of rheumatoid arthritis with synthetic and biological disease-modifying antirheumatic drugs: 2019 update. Ann Rheum Dis. 2020;79:685-99.

3. Schoels M, Wong J, Scott DL, Zink A, Richards P, Landewé R, et al. Economic aspects of treatment options in rheumatoid arthritis: a systematic literature review informing the EULAR recommendations for the management of rheumatoid arthritis. Ann Rheum Dis. 2010;69(6):995-1003.

4. Schipper LG, Vermeer M, Kuper HH, Hoekstra MO, Haagsma CJ, Broeder $A A D$, et al. A tight control treatment strategy aiming for remission in early rheumatoid arthritis is more effective than usual care treatment in daily clinical practice: a study of two cohorts in the Dutch Rheumatoid Arthritis Monitoring registry. Ann Rheum Dis. 2012;71(6):845-50.

5. Grigor C, Capell H, Stirling A, McMahon AD, Lock P, Vallance $R$, et al. Effect of a treatment strategy of tight control for rheumatoid arthritis (the TICORA 
study): a single-blind randomised controlled trial. Lancet. 2004;364(9430): 263-9.

6. Verstappen SMM, Jacobs JWG, van der Veen MJ, Heurkens AHM, Schenk Y, ter Borg EJ, et al. Intensive treatment with methotrexate in early rheumatoid arthritis: aiming for remission. Computer Assisted Management in Early Rheumatoid Arthritis (CAMERA, an open-label strategy trial). Ann Rheum Dis. 2007;66(11):1443-9.

7. Goekoop-Ruiterman YPM, de Vries-Bouwstra JK, Allaart CF, van Zeben D, Kerstens PJSM, Hazes JMW, et al. Clinical and radiographic outcomes of four different treatment strategies in patients with early rheumatoid arthritis (the BeSt study): a randomized, controlled trial. Arthritis Rheum. 2005;52(11): 3381-90.

8. Goekoop-Ruiterman YPM, de Vries-Bouwstra JK, Kerstens PJSM, Nielen MMJ, Vos $K$, van Schaardenburg D, et al. DAS-driven therapy versus routine care in patients with recent-onset active rheumatoid arthritis. Ann Rheum Dis. 2010;69(1):65-9.

9. Schipper LG, van Hulst LTC, Grol R, van Riel PLCM, Hulscher MEJL, Fransen J. Meta-analysis of tight control strategies in rheumatoid arthritis: protocolized treatment has additional value with respect to the clinical outcome. Rheumatology (Oxford). 2010;49(11):2154-64.

10. Stoffer MA, Schoels MM, Smolen JS, Aletaha D, Breedveld FC, Burmester G, et al. Evidence for treating rheumatoid arthritis to target: results of a systematic literature search update. Ann Rheum Dis. 2016;75(1):16-22.

11. Schoels M, Knevel R, Aletaha D, Bijlsma JWJ, Breedveld FC, Boumpas DT, et al. Evidence for treating rheumatoid arthritis to target: results of a systematic literature search. Ann Rheum Dis. 2010;69(4):638-43.

12. Versteeg GA, Steunebrink LMM, Vonkeman HE, ten Klooster PM, van der Bijl $A E$, van de Laar MAFJ. Long-term disease and patient-reported outcomes of a continuous treat-to-target approach in patients with early rheumatoid arthritis in daily clinical practice. Clin Rheumatol. 2018;37(5):1189-97.

13. Brinkmann GH, Norvang V, Norli ES, Grøvle L, Haugen AJ, Lexberg ÅS, et al. Treat to target strategy in early rheumatoid arthritis versus routine care - a comparative clinical practice study. Semin Arthritis Rheum. 2019;48(5):80814.

14. Ramiro S, Landewé RB, van der Heijde D, Sepriano A, FitzGerald O, Ostergaard $\mathrm{M}$, et al. Is treat-to-target really working in rheumatoid arthritis? A longitudinal analysis of a cohort of patients treated in daily practice (RA BIODAM). Ann Rheum Dis. 2020;79(4):453-9.

15. Vermeer M, Kuper HH, Hoekstra M, Haagsma CJ, Posthumus MD, Brus HLM, et al. Implementation of a treat-to-target strategy in very early rheumatoid arthritis: results of the Dutch Rheumatoid Arthritis Monitoring remission induction cohort study. Arthritis Rheum. 2011;63(10):2865-72.

16. Vermeer M, Kuper HH, Moens HJB, Drossaers-Bakker KW, van der Bijl AE, van Riel PLCM, et al. Sustained beneficial effects of a protocolized treat-to-target strategy in very early rheumatoid arthritis: three-year results of the Dutch Rheumatoid Arthritis Monitoring remission induction cohort. Arthritis Care Res. 2013;65(8):1219-26.

17. Steunebrink LMM, Versteeg GA, Vonkeman HE, Ten Klooster PM, Kuper HH, Zijlstra TR, et al. Initial combination therapy versus step-up therapy in treatment to the target of remission in daily clinical practice in early rheumatoid arthritis patients: results from the DREAM registry. Arthritis Res Ther. 2016;18:60.

18. Prevoo ML, van 't Hof MA, Kuper $H H$, van Leeuwen $M A$, van de Putte $L B$, van Riel PL. Modified disease activity scores that include twenty-eight-joint counts. Development and validation in a prospective longitudinal study of patients with rheumatoid arthritis. Arthritis Rheum. 1995;38(1):44-8.

19. Smolen JS, Breedveld FC, Schiff MH, Kalden JR, Emery P, Eberl G, et al. A simplified disease activity index for rheumatoid arthritis for use in clinical practice. Rheumatology (Oxford). 2003;42(2):244-57.

20. Bruce B, Fries JF. The health assessment questionnaire (HAQ). Clin Exp Rheumatol. 2005;23(5 Suppl 39):S14-8.

21. EuroQol Group. EuroQol--a new facility for the measurement of healthrelated quality of life. Health Policy. 1990;16(3):199-208.

22. Pappas DA, Gerber RA, Litman HJ, Gruben D, Geier J, Hua WD, et al. Delayed treatment acceleration in patients with rheumatoid arthritis who have inadequate response to initial tumor necrosis factor inhibitors: data from the Corrona registry. Am Health Drug Benefits. 2018;11(3):148-58.

\section{Publisher's Note}

Springer Nature remains neutral with regard to jurisdictional claims in published maps and institutional affiliations.

\section{Ready to submit your research? Choose BMC and benefit from:}

- fast, convenient online submission

- thorough peer review by experienced researchers in your field

- rapid publication on acceptance

- support for research data, including large and complex data types

- gold Open Access which fosters wider collaboration and increased citations

- maximum visibility for your research: over $100 \mathrm{M}$ website views per year

At BMC, research is always in progress.

Learn more biomedcentral.com/submissions 